\title{
Clinical Reasoning: A 48-year-old woman with confusion, personality change, and multiple enhancing brain lesions
}

James M. Hillis, MBBS, DPhil, * Alex B. Ruan, * Jacob E. Lazarus, MD, PhD, Mary W. Montgomery, MD, and Aaron L. Berkowitz, MD, PhD

Neurology ${ }^{\circledR}$ 2018;90:e1724-e1729. doi:10.1212/WNL.0000000000005484
Correspondence

Dr. Hillis

jhillis@partners.org

\section{Section 1}

A 48-year-old woman was transferred to our service with confusion and a change in her personality. She had presented initially with several days of malaise, abdominal pain, and nonproductive cough. She had also experienced multiple mechanical falls at home and reported weight loss of 20 pounds over 1 month. Her examination was notable for mild epigastric tenderness without guarding, a blunted and indifferent affect, difficulty with multistep commands, and recall of $0 / 3$ objects after 5 minutes. She was otherwise alert and oriented with normal cranial nerve, upper extremity, and lower extremity examinations. CT of the head was performed as part of her initial evaluation (figure, A-D). She had additional imaging given her cough and abdominal pain: CT of the chest demonstrated a right breast mass, and CT of the abdomen and pelvis showed peripancreatic, upper periaortic, and mesenteric masses.

\section{Questions for consideration:}

1. What does the CT reveal and what is the differential diagnosis for the findings?

2. How should additional testing be prioritized? 
Figure CT and MRI of the brain

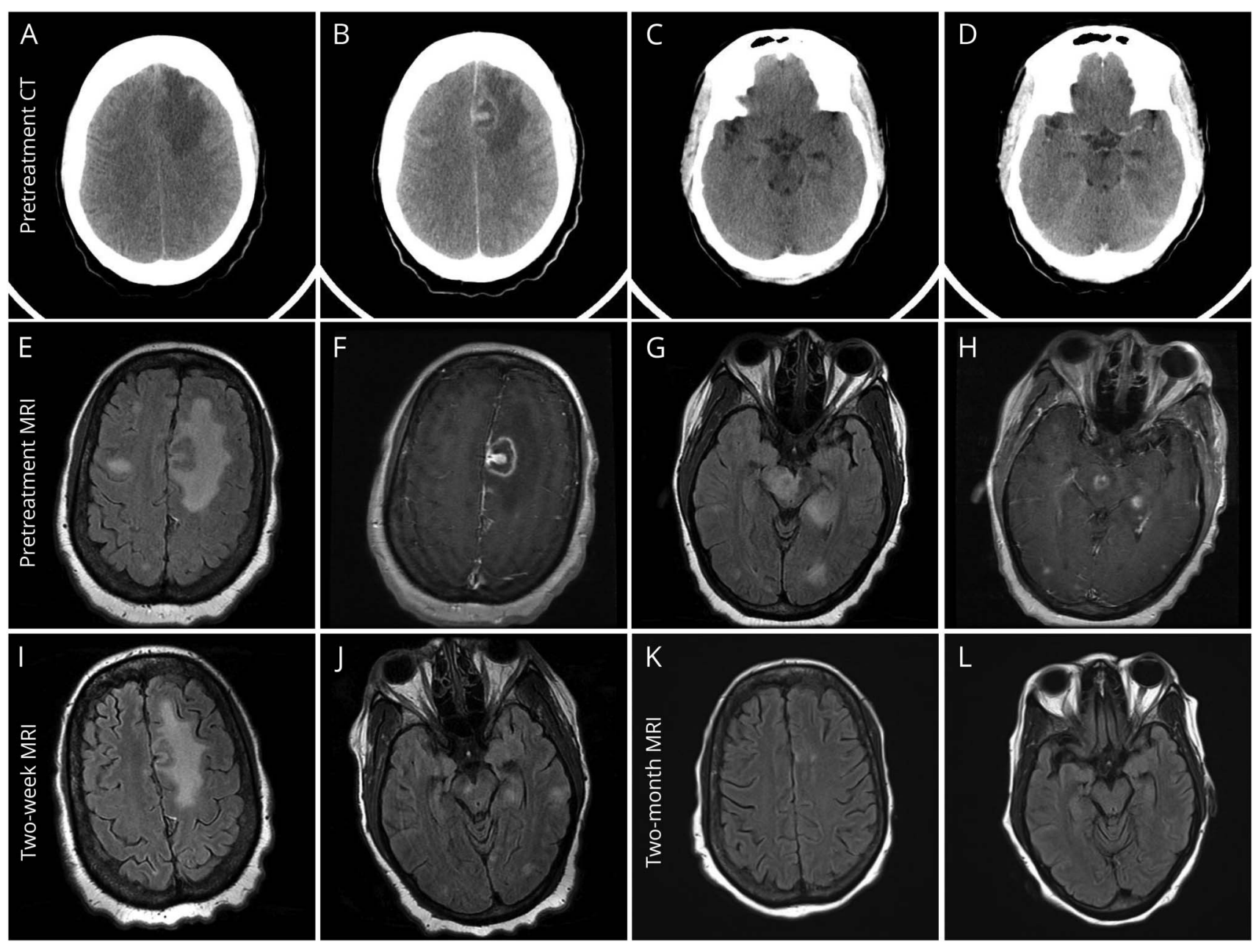

Axial images of intracranial masses in the left frontal lobe $(A, B, E, F, I$, and $K)$ and right midbrain and left temporal lobe $(C, D, G, H, J, L)$. Noncontrast $(A, C)$ and postcontrast $(B, D) C T$ images demonstrate ring-enhancing and nonenhancing hypodense masses. Pretreatment fluid-attenuated inversion recovery ( $E$, $G$ ) and T1-weighted postcontrast $(F, H)$ MRI show ring-enhancing masses with associated edema. Posttreatment fluid-attenuated inversion recovery MRI after 2 weeks $(\mathrm{I}, \mathrm{J})$ and 2 months $(\mathrm{K}, \mathrm{L})$ demonstrate improvement of masses and associated edema. Contrast was not administered during the posttreatment MRIs due to acute kidney injury. 


\section{Section 2}

CT of the head revealed both ring-enhancing and nonenhancing hypodensities associated with edema, the largest of which was in the left frontal lobe with midline shift. Multiple intracranial hypodensities can represent metastases, multifocal infarct or infection, or inflammatory or demyelinating diseases. Contrast enhancement can be seen in all of these etiologies including stroke if subacute and demyelination if acute (although an incomplete ring would be more consistent with demyelination). Ring enhancement with mass effect is more suggestive of malignancy or infection.

Our patient's initial laboratory studies were notable for albumin $2.9 \mathrm{~g} / \mathrm{dL}$ (3.5-5.2), protein $7.6 \mathrm{~g} / \mathrm{dL}$ (6.4-8.3), globulin gap $4.7 \mathrm{~g} / \mathrm{dL}$ (difference between albumin and protein; 2.2-4.2), and white blood cell count 3,600 cells $/ \mu \mathrm{L}$
$(4,000-10,000)$. An elevated globulin gap can be caused by polyclonal gammopathy (e.g., liver disease, viral hepatitis, HIV) or monoclonal gammopathy (e.g., monoclonal gammopathy of undetermined significance, plasma cell or B-cell malignancy). The presence of leukopenia and elevated globulin gap prompted HIV testing that returned positive. Viral load was 74,577 copies/mL and CD4 count was 32 cells/ $\mu \mathrm{L}$ (441-2,156) consistent with profound immunosuppression.

MRI of the brain was obtained (figure, E-H). It showed greater than 20 ring-enhancing lesions with mass effect and edema.

\section{Questions for consideration:}

1. How does the patient's HIV status and CD4 count change the differential diagnosis?

2. What should be the next steps in managing this patient? 


\section{Section 3}

In a patient with HIV, the differential diagnosis of multiple brain lesions depends on the CD4 count. Bacterial abscess and CNS tuberculosis (TB) can occur at any CD4 count, but the risk increases with greater immunosuppression. At a CD4 count $<200$ cells $/ \mu \mathrm{L}$, progressive multifocal leukoencephalopathy (PML) from JC virus can occur. At a CD4 count $<100$ cells/ $\mu \mathrm{L}$, CNS toxoplasmosis, primary CNS lymphoma (PCNSL), and fungal infections such as cryptococcal meningitis can occur; the latter may be associated with cryptococcomas (mass lesions from focal cryptococcal infection). At a CD4 count $<50$ cells $/ \mu \mathrm{L}$, cytomegalovirus (CMV) encephalitis may occur. Of these entities, ring-enhancing lesions can be seen with bacterial abscesses, TB, toxoplasmosis, and PCNSL. CMV encephalitis (which results in periventricular white matter changes) and cryptococcomas (which may show peripheral nodular enhancement) classically do not present with ring-enhancing lesions. PML (which typically causes asymmetric T2 hyperintense lesions juxtacortically and in the middle cerebellar peduncle) usually does not enhance, though enhancement may be seen in the context of immune reconstitution inflammatory syndrome (IRIS).

In areas where $\mathrm{TB}$ is nonendemic, the most common causes of HIV-related ring-enhancing lesions are CNS toxoplasmosis and PCNSL. ${ }^{1}$ PCNSL more commonly affects the periventricular white matter while CNS toxoplasmosis more commonly involves subcortical regions, especially the basal ganglia. They are, however, challenging to distinguish radiologically. CSF PCR analysis can help with diagnosis, although current assays do not have ideal characteristics: CSF
Toxoplasma gondii PCR is $96 \%-100 \%$ specific but only 50\% sensitive ${ }^{2,3}$; CSF Epstein-Barr virus PCR was reported to have $85 \%$ sensitivity and $98 \%$ specificity for PCNSL, ${ }^{2}$ though a more recent publication suggests a positive predictive value of only $29 \% .{ }^{4}$ It is therefore recommended to assess clinical and radiographic response to 14 days of toxoplasmosis treatment, with failure to improve prompting brain biopsy to evaluate for PCNSL. ${ }^{2-5}$ The use of corticosteroids during this period should be avoided as PCNSL may improve radiologically. Pyrimethamine/sulfadiazine is the initial therapy of choice for toxoplasmosis; however, pyrimethamine is not easily available or affordable in the United States given the price charged by its sole manufacturer. ${ }^{3,6}$ Trimethoprim/ sulfamethoxazole, which our patient received, can be used when pyrimethamine is unavailable. ${ }^{3}$

Our patient's lumbar puncture revealed glucose $65 \mathrm{mg} / \mathrm{dL}$, total protein $73.9 \mathrm{mg} / \mathrm{dL}$, red blood cells $4 / \mu \mathrm{L}$, and total nucleated cells $11 / \mu \mathrm{L}$ with $96 \%$ lymphocytes. CSF $T$ gondii PCR was positive, CSF Epstein-Barr virus PCR was negative, CSF cytology and flow cytometry were negative, and CSF mycobacterial culture/smear were negative. Serum studies were notable for positive $T$ gondii immunoglobulin G, negative Cryptococcal antigen, and negative 1-3- $\beta$-d-glucan.

Additional history revealed that our patient had lived most of her life in a TB-endemic country and immigrated to the United States about 5 years prior to presentation.

\section{Question for consideration:}

1. What further diagnostic workup should be performed?

\section{GO TO SECTION 4}




\section{Section 4}

Given the breast and pancreatic masses on CT, our patient underwent diagnostic mammogram and ultrasound-guided breast biopsy that demonstrated a fibroadenoma, and endoscopic ultrasound-guided biopsy of the peripancreatic mass that revealed acid-fast bacilli on smear and TB on culture. Induced sputum demonstrated $\mathrm{TB}$ on nucleic acid amplification test. Both sources of TB were susceptible to rifabutin, isoniazid, pyrazinamide, and ethambutol, and our patient was initiated on this 4-drug regimen.

\section{Questions for consideration:}

1. Could the brain masses be caused by TB?

2. What are important considerations in initiating HIV antiretroviral therapy (ART)?

GO TO SECTION 5 


\section{Section 5}

The most common neurologic manifestations of TB are meningitis, Pott disease (vertebral body involvement), tuberculoma, and spinal meningitis/arachnoiditis. It was therefore possible that some or all of the ring-enhancing masses in our patient represented tuberculomas. Since the treatment for CNS tuberculomas is identical to the treatment for systemic $\mathrm{TB},{ }^{7}$ we continued both $\mathrm{TB}$ and empiric toxoplasmosis treatment.

IRIS is the main consideration when starting ART in a patient with an opportunistic infection. IRIS is a paradoxical worsening of a known underlying infection or an unmasking of an occult infection due to reconstitution of the immune system. The incidence of IRIS depends on the type of opportunistic infection (the highest risk occurs with TB, cryptococcal, CMV, and JC virus infections) and the $\mathrm{CD} 4$ count at the time of treatment (lower CD4 counts have greater risk). ${ }^{7}$ ART is typically started within 2 weeks of initiating TB therapy in patients with a CD4 count $<50$ cells $/ \mu \mathrm{L}$, although it is delayed for 8 weeks in patients with CNS TB. ${ }^{8}$ ART is also typically delayed in the setting of cryptococcal meningitis. ${ }^{3}$ The risk of IRIS is lower with CNS toxoplasmosis and ART is typically started within 2-3 weeks of toxoplasmosis treatment. ${ }^{3}$ The treatment for CNS and systemic TB IRIS is corticosteroids whereas no clear management guidelines exist for CNS toxoplasmosis IRIS given its rarity. ${ }^{3,7}$

After commencing treatment, our patient's mental status fluctuated with a nadir of drowsiness, intermittent ability to follow one-step commands, and minimal one-word responses when speaking. MRI of the brain was performed after 2 weeks of toxoplasmosis treatment and 4 days of TB treatment (contrast was not used due to multifactorial acute kidney injury), demonstrating improvement in the CNS lesions (figure, I and J), which was believed to suggest toxoplasmosis rather than TB as the etiology. She was ultimately started on ART 3 weeks after initiation of toxoplasmosis treatment and 1 week after starting TB treatment. While she did not develop CNS IRIS, she did develop systemic TB IRIS with worsening mediastinal, hilar, and axillary lymphadenopathy, for which she received oral prednisone.

Approximately 2 months after initial presentation, our patient's mental status had improved and she was once again alert and oriented, conversant in full sentences, and able to follow simple commands. She continued, however, to have cognitive deficits such that she was unable to live independently. MRI of the brain demonstrated further improvement (figure, $\mathrm{K}$ and $\mathrm{L}$ ).

\section{Discussion}

The differential diagnosis of a brain mass expands in an immunocompromised patient. There is a stepwise increase in possible diagnoses as the CD4 count decreases in a patient with HIV. With the introduction of ART, HIV-associated toxoplasmosis hospitalizations in the United States decreased from 10,583 in 1995 to 3,643 in $2001 .^{9}$

The gold standard for diagnosing a brain mass is biopsy, although it carries the risk of perioperative morbidity and mortality. The diagnosis of CNS toxoplasmosis can usually be made without biopsy; it is based on CSF studies and empiric treatment response, with over $90 \%$ of patients responding within 2 weeks. ${ }^{2-5}$

This patient had been initially transferred to our service with concern for metastatic cancer, and her case highlights the importance of evaluating HIV status for any patient with unexplained neurologic deficits. In fact, the Centers for Disease Control and Prevention currently recommends HIV screening on all patients aged $13-64$ years as part of routine care. ${ }^{10}$

\section{Author contributions}

James M. Hillis and Alex B. Ruan drafted and revised the manuscript. Jacob E. Lazarus and Mary W. Montgomery revised the manuscript. Aaron L. Berkowitz drafted and revised the manuscript. All authors provided clinical care for the patient.

\section{Study funding}

No targeted funding reported.

\section{Disclosure}

Dr. Hillis, Mr. Ruan, Dr. Lazarus, and Dr. Montgomery report no disclosures relevant to the manuscript. Dr. Berkowitz reports no disclosures relevant to the manuscript but receives royalties from Clinical Pathophysiology Made Ridiculously Simple (Medmaster), The Improvising Mind (Oxford University Press), and Clinical Neurology and Neuroanatomy: A Localization-Based Approach (McGraw-Hill). Go to Neurology.org/N for full disclosures.

\section{References}

1. Ammassari A, Cingolani A, Pezzotti P, et al. AIDS-related focal brain lesions in the era of highly active antiretroviral therapy. Neurology 2000;55:1194-1200.

2. Antinori A, Ammassari A, De Luca A, et al. Diagnosis of AIDS-related focal brain lesions: a decision-making analysis based on clinical and neuroradiologic characteristics combined with polymerase chain reaction assays in CSF. Neurology 1997;48:687-694.

3. Panel on Opportunistic Infections in HIV-Infected Adults and Adolescents. Guidelines for the Prevention and Treatment of Opportunistic Infections in HIV-infected Adults and Adolescents: Recommendations from the Centers for Disease Control and Prevention, the National Institutes of Health, and the HIV Medicine Association of the Infectious Diseases Society of America. Available at: aidsinfo.nih.gov/contentfiles/lvguidelines/adult_oi.pdf. Accessed November 11, 2017.

4. Ivers LC, Kim AY, Sax PE. Predictive value of polymerase chain reaction of cerebrospinal fluid for detection of Epstein-Barr virus to establish the diagnosis of HIV-related primary central nervous system lymphoma. Clin Infect Dis 2004;38:1629-1632.

5. Porter SB, Sande MA. Toxoplasmosis of the central nervous system in the acquired immunodeficiency syndrome. N Engl J Med 1992;327:1643-1648.

6. Alpern JD, Song J, Stauffer WM. Essential medicines in the United States: why access is diminishing. N Engl J Med 2016;374:1904-1907.

7. Muller M, Wandel S, Colebunders R, et al. Immune reconstitution inflammatory syndrome in patients starting antiretroviral therapy for HIV infection: a systematic review and meta-analysis. Lancet Infect Dis 2010;10:251-261.

8. Nahid P, Dorman SE, Alipanah N, et al. Official American Thoracic Society/Centers for Disease Control and Prevention/Infectious Diseases Society of America Clinical Practice Guidelines: treatment of drug-susceptible tuberculosis. Clin Infect Dis 2016; 63:e147-e195.

9. Jones JL, Roberts JM. Toxoplasmosis hospitalizations in the United States, 2008, and trends, 1993-2008. Clin Infect Dis 2012;54:e58-61.

10. Branson BM, Handsfield HH, Lampe MA, et al. Revised recommendations for HIV testing of adults, adolescents, and pregnant women in health-care settings. MMWR Recomm Rep 2006;55:1-17; quiz CE11-14. 


\section{Neurology}

\section{Clinical Reasoning: A 48-year-old woman with confusion, personality change, and multiple enhancing brain lesions}

James M. Hillis, Alex B. Ruan, Jacob E. Lazarus, et al.

Neurology 2018;90; 1724-e1729

DOI 10.1212/WNL.0000000000005484

\section{This information is current as of May 7, 2018}

\section{Updated Information \& Services}

References

Subspecialty Collections

Permissions \& Licensing

Reprints including high resolution figures, can be found at: http://n.neurology.org/content/90/19/e1724.full

This article cites 9 articles, 2 of which you can access for free at: http://n.neurology.org/content/90/19/e1724.full\#ref-list-1

This article, along with others on similar topics, appears in the following collection(s):

\section{All Infections}

http://n.neurology.org/cgi/collection/all_infections HIV

http://n.neurology.org/cgi/collection/hiv

Parasitic infections

http://n.neurology.org/cgi/collection/parasitic_infections

Information about reproducing this article in parts (figures,tables) or in its entirety can be found online at:

http://www.neurology.org/about/about_the_journal\#permissions

Information about ordering reprints can be found online:

http://n.neurology.org/subscribers/advertise

Neurology ${ }^{\circledR}$ is the official journal of the American Academy of Neurology. Published continuously since 1951, it is now a weekly with 48 issues per year. Copyright @ 2018 American Academy of Neurology. All rights reserved. Print ISSN: 0028-3878. Online ISSN: 1526-632X.

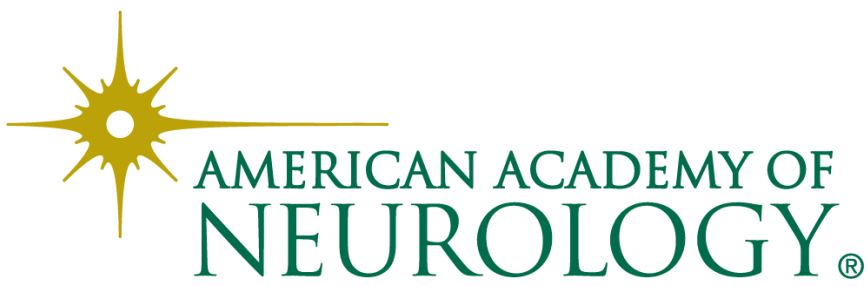

